\title{
INTRAHISTORIA, \\ COTIDIANIDAD \\ Y LOCALIDAD
}

\section{INTRA-HISTORY, THE EVERYDAY AND THE LOCAL}

\section{CELSO MEDINA*}

\section{RESUMEN}

Nos proponemos con este artículo colocar en la discusión el polémico concepto de intrahistoria, que introdujera el filósofo español Miguel de Unamuno en su libro En torno al casticismo, editado en 1895 . Nuestro objetivo es correlacionarlo con la visión de la historia que en el siglo XX se denominó microhistoria, cuyo ideólogo principal es el italiano Carlo Ginzburg. Partimos de una premisa: la intrahistoria unamuniana concibe la historia desde una versión minimalista de los eventos sociales, lo que nos ayuda a vincular su concepto con el estudio de la cotidianidad y de lo local. Para Unamuno, la historia debía interesarse en los caminos que protagonizaron sus actores periféricos; es decir, en la senda que recorrieran aquellos hombres que hacen la historia de manera inconsciente. O lo que es lo mismo: por los hombres que no aspiran al título de héroes. Por ello apuesta por la "tradición viva", la tradición paradojalmente del presente. Y además, observamos en esas ideas unamunianas, un rechazo a la historia trágica, que se urde a fuerza de intrigas. ¿Dónde se encuentran el pensamiento de Unamuno y de Ginzburg? Creemos que coinciden en la reducción de la escala del estudio de la historia. Para ellos el hecho histórico no es el fresco monumental que mitifica a políticos, militares y sacerdotes, héroes tradicionales de la historia; es más bien una demótica, en el sentido que lo entendió el español, o el estudio de la "cultura de las clases subalternas", según la visión del italiano. Correlacionar las ideas de ambos autores puede ser una vía bastante productiva para entender la complejidad de la cultura local, a la luz del clima cultural latinoamericano.

Palabras clave: Intrahistoria, microhistoria, culturas locales, la desdramatización de la historia.

* Doctor en Filología Hispanoamericana (Universidad de Salamanca). Profesor de la Universidad Pedagógica Experimental Libertador, Instituto Pedagógico de Maturín. Venezuela. E-mail: medinacelso@cantv.net 


\begin{abstract}
In this article, we place in discussion the polemical concept of intra-history, introduced by the Spanish philosopher Miguel de Unamuno in his book En torno al casticismo, edited in 1895. Our objective is to correlate it to the vision of history developed in the $20^{\text {th }}$ century called micro-history, whose principal ideologue was the Italian Carlo Ginzburg. We begin with the following premise: Unamuno's intra-history views history from a minimalist version of social events, which helps us to link his concept to the study of the everyday and the local. For Unamuno, history should be interested in the routes whose principle leading roles are played by its peripheral actors; that is to say, the paths followed by those men who make history in an unconscious manner, by those who do not aspire to the title of heroes. And so the writer places his bets on the "living tradition", the paradoxical tradition of the present. Furthermore, we can observe in these ideas of Unamuno a rejection of tragic history which is woven through the force of intrigues. Where do Unamuno's and Ginzburg's thought meet? We believe that they coincide in the reduction in scale of the study of history. The historical event is not the monumental fresco that encourages the mythification of politicians, military men and priests, the traditional heroes of history; it is more precisely demotic in the sense understood by the Spaniard, or in the study of "the cultures of the subaltern classes", according to the vision of the Italian. Correlating the ideas of both writers can be a productive path in understanding the complexity of local culture in light of the Latin American cultural climate.
\end{abstract}

Keywords: Intra-history, micro-history, local cultures, the des-dramatization of history.

Recibido: 18.05.2008. Aprobado: 13.07.2009.

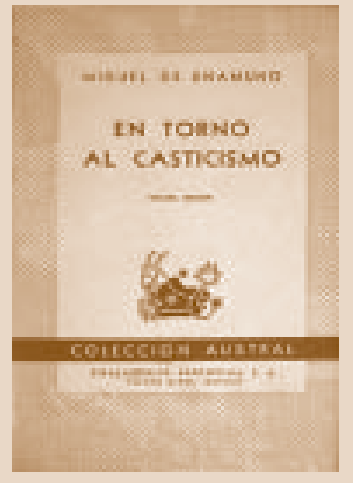

$\mathrm{D}$ IFÍCIL es navegar en el proceloso mar ensayístico de Miguel de Unamuno. Uno corre siempre el riesgo de naufragar en imágenes, metáforas y en aporías. Y más complicado es procurar extraer de esa ensayística conceptos estables que puedan servirnos para debatir en el campo de la complejidad epistemológica contemporánea.

Procuraremos desandar el hilo de Ariadna que teje el ensayo "La tradición eterna”, texto que se inserta en el libro del filósofo español En torno al casticismo ([1895] 2000). Atenderemos al consejo del propio filósofo, quien nos alerta sobre su método: "el de la afirmación alternativa de los contradictorios”, con el que ensayaremos un concepto de intrahistoria.

La idea de la intrahistoria unamuniana habría que ubicarla en la España que vivía sus últimos días imperialistas. El libro de Unamuno junto al de José Ortega y Gasset, España invertebrada (1921), conforman una mirada descarnada al exceso de heroísmos que había invadido la historia hispánica. Fue escrito a tres años del 1898, año en que ocurre la afrenta de ver en las costas cubanas buena parte de la armada española hecha añicos por los bom- 
bardeos norteamericanos, con lo que la nación europea perdía su última colonia en América.

El título del libro de Unamuno puede llevar a equívocos. Su defensa del casticismo resulta un juego aporético. No es una loa al nacionalismo, ni mucho menos la postulación de una cultura de la casta hispánica. Es, contrariamente, una apuesta por un punto intermedio donde los extremos castizos y europeos resalten "para que el medio tome vida" en el espíritu de los lectores. Criticando el gesto de Renán, quien llegó a exhortar a Francia para que se dejara conquistar por Alemania, afirma:

Mas no hace falta conquista, ni la conquista purifica, porque, a su pesar $y$ no por ella, se civilizan los pueblos $(31)^{1}$.

Esa postura antiimperialista es coherente con su visión de la historia, que pretende trocar por su concepto de intrahistoria. Recusa Unamuno una historia que se postula como fragmentos discontinuos, liderizada por supuestos defensores de culturas puras. Y en su refutación llega a encomiar las culturas bárbaras:

... la invasión de los bárbaros fue el principio de la regeneración de la cultura europea ahogada bajo la senilidad del imperio decadente (39).

El filósofo español cree en una historia continua, que vive en un presente vivo. No en un relato que se obsesiona con el pasado. Ese continuum lo construye lo que llama "la tradición eterna". Recurriendo a una metáfora, urde el concepto de esa tradición:

... las olas de la historia, con su rumor y su espuma que reverbera el sol, ruedan sobre un mar continuo, hondo, inmensamente más hondo que la capa que ondula sobre un mar silencioso y a cuyo último fondo nunca llega el sol (41).

La intrahistoria es la historia del adentro, de ese zócalo marino cuya temporalidad discurre en silencio. Se refiere, entonces, a un discurrir eterno, que no cesa de acarrear sedimentos al fluir callado. Ese sedimento ha sido obliterado. La historia se ha desarrollado entonces como un ruido que sólo da fe de la existencia de una superficie. De allí que:

\footnotetext{
${ }^{1}$ Para el presente texto hemos tenido en cuenta la edición de En torno al casticismo, publicada en Madrid por la Editorial Alianza, del año 2000. Cuando la citemos nos referiremos a ella, y sólo indicaremos su paginación.
}

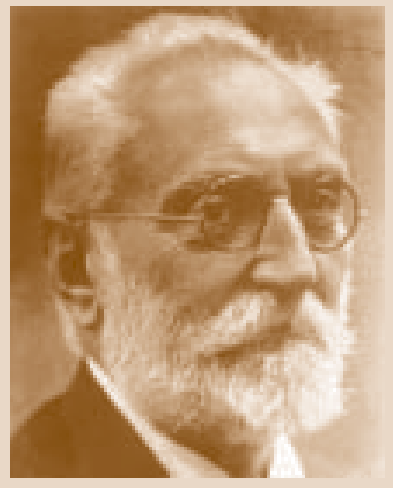

M. de Unamuno

jose ortege y gasset

espan̄a

invertebrada

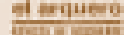

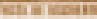


Todo lo que cuentan a diario los periódicos, la historia toda del "presente momento histórico", no es sino la superficie del mar, una superficie que se hiela y cristaliza en los libros y registros, y, una vez cristalizada así, una capa dura, no mayor con respecto a la vida intra-histórica que esta pobre corteza en que vivimos con relación al inmenso foco ardiente que lleva dentro (41).

No es azaroso que Unamuno aluda al periodismo, la actividad comunicativa moderna que ha monopolizado la opinión pública, y que es fuente estelar de la historia política. Nada más apropiado para vincularse con la metáfora de la "superficie bullanguera", que concibe la vida como un juego de intrigas. Por ello, para dar carnadura a su metáfora, dice:

Esos periódicos nada dicen de la vida silenciosa de los millones de hombres sin historia que a todas horas del día y en todos los países del globo se levantan a una orden del sol y van a sus campos a proseguir la oscura y silenciosa labor cotidiana y eterna, esa labor que como la de las madréporas suboceánicas echa las bases sobre que se alzan los islotes de la historia (41).

De modo que se apuesta por la inmersión en ese mar de fondo, "no en la tradición mentida", forjada con el parque documental que han ido acumulando los que viven en la espuma superficial de esa ribera. En ese "mar quieto" se produce la intrahistoria. Unamuno ilustra su argumentación con ejemplos de la historia de España. Afirma que la Restauración de 1875, que repuso al monarca Alfonso XII, no reanudó la historia de ese país. Éste no se paralizó, a menos que se entendiera a España como aquella en la que vivían los implicados en la Guerra Carlista.

... fueron millones de hombres que siguieron haciendo lo mismo que antes, aquellos millones para los cuales fue el mismo sol después del 29 de septiembre de 1868, las mismas labores, los mismos los cantares con que siguieron el surco de la arada. $Y$ no reanudaron en realidad nada, porque nada se había roto (42).

La historia, en la visión unamuniana, ha sido secuestrada por los que "se hacen sordos al silencio". De manera que podemos aproximarnos a un concepto de la intrahistoria. Unamuno nos da claves capitales: se asocia en primer lugar a la "tradición eterna", ese fondo a donde no llega el sol, que se edifica en un continuum. Es, también, "la sustancia de la historia... la manera de concebirla en vivo... lo inconsciente de la historia". 
¿Qué modelo de historia puede derivarse de este concepto? Podríamos describirlo a partir de las siguientes características:

\section{Una historia minimalista}

Afirma Unamuno que hay que "buscar lo eterno en el aluvión de lo insignificante". Se trata de una historia con personajes sin pretensiones historicistas. De hombres que viven para impulsar ese continuum. Todos los hechos tienen, entonces, significaciones porque son la tarea de una noria histórica incesante. ¿Cómo queda el reparto social de los eventos instaurado por el historicismo clásico? Anulado. De modo que desaparecen los universalismos; y sólo tienen cabida los haceres de las localidades. La tarea del sujeto histórico abandona el heroísmo.

\section{Una historia con protagonismos horizontales}

El héroe es el paradigma más antiguo de la historia occidental. Su formalización teórica más precisa la podemos hallar en Aristóteles. Para el filósofo griego encarnaba la virtud conducente a la gracia de los dioses. Por ello, fue el modelo emulado (o imitado) en la tragedia, puesto que él sólo protagoniza acciones buenas. El antihéroe pertenecía al género "innoble" de la comedia. Ese héroe puesto en la escena trágica era la fuente de la catarsis; los que asistían al teatro helénico empatizaban con él, sufrían con él, sólo porque su sufrimiento devenía de los dioses, no de los hombres. Su belleza se patentizaba en la armonía, en el orden y su cuerpo era el emblema de la idea generalizada del hombre glorioso. En ese camino no sólo se colocaron los historiadores; también lo hicieron los novelistas. Emulando a los grandes historiadores clásicos, urdieron tramas focalizadas en el héroe. Ėste pasó a ser el astro, alrededor del cual giraba el mundo. Los relatos no fueron más que narraciones de protagonismos únicos, en los cuales un ser se distinguía de su congéneres y liderizaba una carrera hacia una meta: bien sea hacia su gloria, bien hacia su derrota. El tiempo era también una metafísica, donde la vida se coronaba en un final. Ni siquiera en Marc Bloch, un historiador de inequívoca tendencia pluriculturalista, ese afán espectaculista se obvia. Al otorgarle a la historia una cualidad estética, destaca que la misma

... se debe a que el espectáculo de las actividades humanas, que forma su 
objeto particular, está hecho, más que otro cualquiera, para seducir la imaginación de los hombres (1988: 12). (Destacado nuestro).

La historia es entonces "el espectáculo", que necesita de estrategias "seductoras". Por ello se ve obligada a convertir a sus protagonistas en héroes, cuyas hazañas impacten en el escenario donde acuden los espectadores ávidos de intrigas.

Frente a ese modelo, Unamuno propone una intrahistoria sin héroes, en la que las jerarquías de los protagonismos desaparecen. El hacer intrahistórico es una tarea de todos. Todos los hombres importan en tanto que contribuyen a impulsar el continuum de la tradición eterna.

\section{Una historia de perspectivas plurales}

La historia occidental ha pretendido imponerse como la historia única. Y desde esa visión mira las otras historias. Ella observa los acontecimientos como una línea que culminará en algún punto. Y por ello hace de sus héroes un ser que se obsesiona buscando ese punto. La historia, entonces, es tiempo físico y, como tal, metafísica. El héroe es, pues, un redentor, un buscador de griales, que marcha hacia delante y mira el pasado sólo para apoyar su marcha hacia la meta final.

El relato histórico terminó convirtiéndose en la narración de una teleología. Para Paul Veyne (1984), la historia logró "confundir los resultados con la meta”.

La historia por mucho tiempo fue el fragmento que reportaba los avatares del poder. Por ello el héroe era un ser mayestático, idealizado con miras a describir la carrera hacia la meta del control de los estados.

En la visión unamuniana, la historia no es el relato monológico, cuya única voz acalla el tinglado que armoniza el continuun intrahistòrico. Para tal efecto, las fuentes varían volcándose hacia la productividad de sentido de "la vida silenciosa de los millones de hombres sin historia que a todas horas del día y en todos los países del globo se levantan a una orden del sol”.

\section{Una historia sin drama}

La intrahistoria no es un relato de intrigas, sino el reporte de la cotidianidad, que puede despertar interés sin que se venda emvasada en escándalos. Im- 
plica la abolición del predominio de la política en la narración historicista. Esa historia que se vanagloria de las conquistas, que habla de vencidos y vencedores, va a ser sustituida por la saga de la cotidianidad. Unamuno critica acerbamente la curva trágica aristotélica, que hace de los hechos históricos un espectáculo donde necesariamente tiene que haber hombres derrotados. En ese sentido, afirma:

Tenemos tan deformado el cerebro, que no concebimos más que ser amo o esclavo, o vencedor o vencido, empeñándonos en creer que la emancipación de éste es la ruina de aquél (32).

En ese esquema historicista heredado del mundo grecorromano, es frecuente jugar al clímax y la verticalización de los protagonismos. El héroe, su piedra fundacional, está concebido para matar o dejarse matar. Visualizamos en la obra de Unamuno un deseo de que la historia deje de ser la descripción de los partes de guerra, para volcarse a registrar la historia que transcurre sin aspavientos.

El Unamuno que escribe En torno al casticismo es un joven de 31 años, vecino de Salamanca, ciudad integrista, a donde arribó en 1891 como profesor de su Universidad, y en donde fuera víctima de una férrea hostilidad, sobre todo cuando en 1894 se adhiere al Partido Socialista. El joven bilbaíno vive los días en que se debate la última guerra independendista contra España en América, la de Cuba. En un texto publicado en 1896, un año después de que aparecieran sus ensayos en la revista La España M oderna, que conformaron después su libro (editado por primera vez en 1900), Unamuno calificaría esa guerra de "estúpida y brutal". Y reitera su rechazo a una historia que se degusta en la ruina de los otros:

Cada vez que alguien habla de autonomía o de otras libertades, alzan el grito al cielo los patrioteros y toda laya de los que pescan en río revuelto y repiten en mil diversos tonos que no es ésta la ocasión de concesiones, que de lo que se trata es de romperles la crisma a los insurrectos (citado por Rabaté, 1999: 162).

Julián Santano Moreno (2003) conecta este libro de Unamuno con el pensamiento tradicionalista de Menéndez Pidal, estableciendo un parangón del concepto "estado latente" (pidaldiano) con la intrahistoria. Esa coincidencia estriba en dos visiones claves: primero, el rechazo a una mera historia de archivos, que conlleva un cambio hacia una historia de lo "humilde", y segundo, la consideración de la literatura como la expresión del 


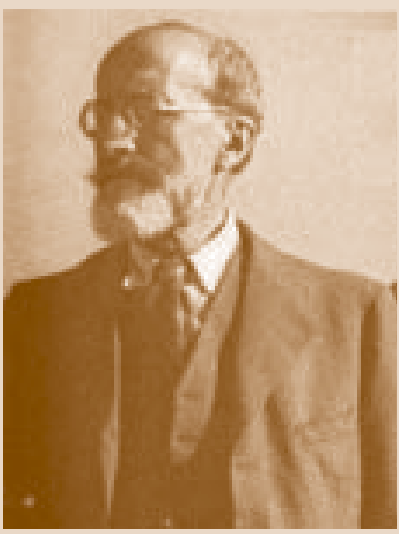

Menéndez Pidal alma popular, mucho más valedera que la historia. La historia existe en la "tradición eterna", es un presente permanente que en la visión unamuniana vive en el zócalo del mar, presta siempre a emerger. La intrahistoria experimenta su latencia en la lengua hablada, no en una escritura que sólo se confía en las tempestades de esa superficie marina, cuyas olas tempestuosas se alientan por la crispación heroica. Unamuno asocia su concepto con "el lenguaje soto-literario o intraliterario" (22), expresado en la literatura popular. Esas ideas se explayarán aún más en textos posteriores: en su novela Paz en la guerra (1897), "Sobre el cultivo de la demótica" (1896), "Vida del romance castellano" (1900).

Moreno encuentra las mismas ideas de la tradición en Unamuno y en Menéndez Pidal. "La hondura (...) es un componente de la imagen empleada por Unamuno para expresar el concepto de intrahistoria” (791). El “estado latente" tiene una multisecular duración. La idea de lo oculto, pero siempre presto a emerger, es lo que impele a estos investigadores de la demótica a auscultar la tradición popular, para acceder a ese zócalo donde pervive la tradición eterna. Ambos se ven obligados a abandonar el terreno de la filología para adentrarse al complejo mundo de la etnografía, donde los indicios son más válidos que la letra fijada por la cultura devenida del oleaje superficial de la historia.

¿Cuáles serían las huellas de esa visión de la historia unamuniana presentes en la discusión de nuestra contemporaneidad? Diríamos que su impacto podríamos localizarlo en la discusión muy postmoderna de los conceptos de cotidianidad y de localidad, conceptos opuestos al trascendentalismo y universalismo del historicismo moderno.

La historia adquirió su estatuto de cientificidad como lo hicieron todas las ciencias modernas: cercando su objeto de estudios, fragmentándolo, para de esa manera cosificarlo, dejándolo dócil ante la "mirada" de su investigador. El mundo que era variado y plural, el historiador lo sometió al cosmos mínimo y reducido de los poderes constituidos. La pantalla que revela la realidad histórica se convierte en un fabricante de universalismos, construidos por espacios que inicialmente fueron localidades y que luego, gracias al poder, plenó el universo con sus teleologías.

La historia se convierte, entonces, en el panteón de los héroes, donde no hay lugar para lo cotidiano ni para los localismos. Vida cotidiana y localidad fueron los primeros exiliados de la naciente ciencia.

Lo cotidiano trabaja en un espacio paradójico. Es rutina, pero también es cambio. En él se urde la trama del mundo, que conserva, cambia y desecha experiencias. En justicia, es allí donde realmente acontece la historia. 
Es donde vive el ser "de carne y hueso" unamuniano; es allí donde, según Émile Cioran, cae el tiempo horadando el cuerpo material del hombre. Para Agnes Heller, "la vida cotidiana es la reproducción del hombre particular" (2002: 41). Pero esa particularidad se tensa o se armoniza con lo ya dado, puesto que "todo hombre al nacer se encuentra en un mundo ya existente, independiente de él" (ídem). Recurriendo a Henri Lefèvbre, esta filósofa húngara comparte la idea de que la vida cotidiana es un espacio donde median el individuo, la naturaleza y la sociedad. El hombre particular y el hombre genérico conviven, entonces, en la cotidianidad. De manera que:

La vida cotidiana es el conjunto de las actividades que caracterizan las reproducciones particulares creadoras de la posibilidad global y permanente de la reproducción social (ídem).

La intrahistoria vive una experiencia fronteriza con la cotidianidad. Ella consigue su continuum ".. de la vida silenciosa de los millones de hombres sin historia que a todas horas del día y en todos los países del globo se levantan a una orden del sol". O lo que es lo mismo: su tradición eterna, su presente vivo. Pero a pesar de que, como dice Heller, "en toda sociedad hay, pues, una vida cotidiana; sin ella no hay sociedad" (1979: 197), el empeño de la historia es desecharla porque ella alejaría al historiador de la totalidad y del universalismo.

Carlo Ginzburg, historiador italiano, impulsa la llamada microhistoria, ubicándose en el camino intrahistórico que iniciara en 1895 Miguel de Unamuno. Su indagación va a ese "mar de fondo", acallado por la historia espectacular occidental, para hacer que emerja la "historia inconsciente", la de aquellos personajes que han sobrellevado el peso de la historia sin aspirar a ocupar el sitial de héroe. El queso y los gusanos, libro disparador de la corriente historicista que pregonó Ginzburg, está sazonado con ese ingrediente unamuniano. Publicado en 1976, ha dejado una trascendente estela en el hacer histórico contemporáneo, hasta el punto de que pudiéramos señalar que es la piedra de toque del historicismo postmoderno.

El libro en cuestión pone en la misma escena la cotidianidad, el localismo y la vida de los seres periféricos cuyas voces fueron silenciadas por la historia clásica. Ya en los inicios de la Escuela de los Annales, nos tropezamos con la resurrección de la metáfora unamuniana del "mar profundo". Uno de los más importantes impulsores de la llamada historia de las mentalidades y miembro de la referida escuela, Fernand Braudel, utiliza la misma metáfora en su libro El M editerráneo y el mundo mediterráneo de la época de

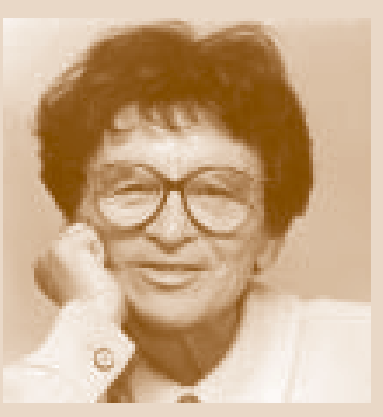

A. Heller

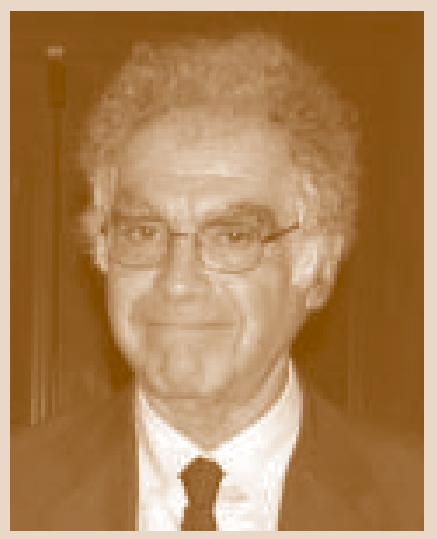

C. Ginzburg 
Felipell, publicado en 1949. Y su concepción de las duraciones históricas se definen como la inconsciencia colectiva, de esa parte latente (recordemos a Ménendez Pidal) que el historiador debe develar a través de su particular hermenéutica. El acceso a las mentalidades laboró tesoneramente desde el espacio de las latencias que se refugiaron no sólo en el espacio político, sino también en el complejo mundo de las religiones, de los ritos y de las fiestas populares.

Jim Sharpe (1999) se interesa en "la historia desde abajo", la misma historia de actor anónimo unamuniano. Este historiador apunta importantes hitos en la conformación de esa corriente historicista. En el siglo XIX detecta en las cartas del soldado William Wheeler, del regimiento 51 que combatió contra Bonaparte y lo venció en Waterloo (1815), el desplazamiento de los testimonios históricos hacia la zona de una periferia, cuyos intereses y visión de mundo eran absolutamente diferentes, por ejemplo, a los del general Wellington ${ }^{2}$, máximo jefe de esa batalla, a quien la historiografía oficial le otorgó un espacio en el santoral heroico británico. El reporte de ese soldado se sitúa en la periferia dramática. El cigarro que atenúa su frío es más valioso que las armas y el bombardeo. Y su relato dista mucho de la ejemplaridad: el bando vencedor (el británico) saquea, roba en la ropa de los cadáveres, entre otras acciones poco edificantes. En el afán de equiparación del personaje de arriba y el de abajo, Sharpe sostiene:

Los libros de historia no dicen que Wellington ganó la batalla de Waterloo. En cierto sentido, William Wheeler y miles como él la ganaron igualmente (1999: 39).

Sharpe alerta sobre el uso del historicismo de los de abajo. Le preocupa una historia que cosifica al personaje periférico, al reducir su complejidad a su rol de obrero, de damnificado, de inmigrante, etc., cuya vida cotidiana se anula en pro de lo genérico. Se genera una heroicidad invertida: los nuevos titanes es la clase explotada. Y podríamos agregar que esa simplificación de la cultura subalterna trasciende en el genealogismo de Foucault, quien hace de los lumpem excluidos los héroes de su indagación epistemológica. Hay en esa visión, ciertamente moral paternalista, casi una piedad cínica. Diríamos también que ni siquiera el marxismo se salvaría de esa mirada paternalista. Su redención clasista obedecería al mismo esquema de una historia que centraliza sus relatos en los espacios de poder. El proletariado forma

\footnotetext{
${ }^{2}$ El duque de Wellington fue el general británico que derrotó a Napoleón en la crucial batalla de Waterloo, el 18 de junio de 1815 .
} 
parte de la periferia; pero la historia marxista quiere hacer de ese proletario el nuevo héroe, y donde hay héroes hay tragedia y, por ende, hay derrotados.

M ontaillou (1975), de Emmanuel Le Roy Ladurie, parece convencer más a Sharpe, puesto que ha dejado a un lado el moralismo paternalista y se apresta a indagar a través de actas inquisitoriales la vida cotidiana de una comunidad para aproximarse a su mentalité.

Es por ello que no deja de sorprendernos el libro de Ginzburg. Su Domenico Scandella es un molinero alfabetizado, poseedor de una compleja ideología, donde se entrevera la cultura popular y la alta cultura. No es gratuito el subtítulo: “El cosmos, según molinero del siglo XVI”. Una mirada sobre el Renacimiento inquisitorial arroja una desmitificación de aquel ideal que ubica a los oprimidos y opresores, sembrados estáticamente en sus espacios culturales. Al igual que Le Roy Ladurie, el historiador italiano levanta su universo de estudio a partir de las actas de la Inquisición que dan testimonio de los dos juicios seguidos contra Menocchio. Y es necesario que tomemos partido por una de las concepciones de ideología que se mercadean en la epistemología. No seguimos al pie de la letra el concepto marxista, según el cual toda ideología es reaccionaria, por cuanto siempre es una falsa visión del mundo (Cfr. Ideología alemana). Nuestra idea de ideología tiene que ver con la posesión de una mirada y un estar en el mundo, que se enhebra en medio de contradicciones y complejos desarrollos. Menocchio es un personaje subalterno atípico del Renacimiento: lee libros, con cuyas ideas arma una estrambótica genealogía:

Yo he dicho que, por lo que yo pienso y creo, todo era un caos... y que aquel volumen poco a poco formó una masa, como se hace el queso con la leche, $y$ en él se formaron gusanos, y estos fueron los ángeles; y la santísima majestad quiso que aquello fuese Dios y los ángeles... (Ginzburg, 2000: 92).

Lo que reporta Ginzburg es la puesta en escena de la ideología de un molinero, el mundo de las clases subalternas, tradicionalmente execradas del interés historicista. Esa ideología es una magmática realidad (utilizando ideas de Basarab Nicolescu), compuesta, según Aguirre Rojas (2003) por

... una suerte de palimpsesto múltiple, conformado por elementos culturales de muy heterogéneas duraciones y vigencias históricas, y articulado siempre de maneras complejas, que además están dentro de un proceso de constante refuncionalización y transformación sistemáticas.

Ese "palimpsesto" nos evoca "el mar silencioso" de Unamuno. Ginzburg 
afirma en el prefacio de su libro que le entusiasmó "una vida transcurrida en el más complejo anonimato" (2000: 9). El silencio sonoro, ese oxímoron tan del barroco, sigue siendo el puente entre Ginzburg y Unamuno. Pero si Unamuno idealiza la lengua popular, convirtiéndola en la resguardadora por excelencia de "la tradición viva", el italiano recurre a lo que aprendió con sus maestros de la Escuela de los Annales: al método de la crítica de fuentes. Combinará la filología y la etnografía. Su hermenéutica a la vez que mira los textos, interpreta observando atentamente los contextos, sin convertirlos en a priori oscurecedor. Se pudiera criticar en Ginzburg el uso de las actas inquisitoriales, textos devenidos del poder. Pero lo que apreciamos en él es a un agudo develador de las hendijas que se esconden en la historia tradicional. Afirma Ginzburg que

Los expedientes de los dos procesos en que se vio encartado a quince años de distancia nos facilitan una elocuente panorámica de sus ideas y sentimientos, de sus fantasías y aspiraciones (2000: 9).

Acceder a esa "elocuente panorámica" genera una puesta en escena de la diversidad discursiva que circula en los juicios. Historiar es entonces internarse en una compleja semiosis, donde Sherlock Holmes o Freud aportan más que Hegel o Dilthey. Diría posteriormente Ginzburg en su libro M itos, emblemas, indicios (1999): "Cuando las causas no son reproducibles, sólo cabe inferirlas de los efectos" (157). Su método indicial se impone, haciendo hablar el pasado a partir de las largas indagatorias donde Menocchio e inquisidores se cuecen en un caldo de productivas contradicciones.

La corriente historicista que contribuyó a fundar Ginzburg, la microhistoria, recoge en buena medida todos los deseos de despojar a la historia de sus obsesiones generalizadoras y heroicas. Giovanni Levi (1999) sintetiza esta corriente a partir de tres prácticas: la reducción de la escala de observación, el análisis microscópico y el estudio intensivo del documento. Ginzburg apuesta casi todo por una pormenorizada revisión de las actas de los juicios inquisitoriales que terminaron condenando a Menocchio. Estamos, entonces, frente a un destronamiento de aquello que Roger Chartier (1994) llamó "quasi personajes"; es decir, entidades abstractas que reducen al hombre a mero engranaje de una máquina social.

Gracias a la microhistoria, la historia se emparenta con la novela, porque esas "entidades" se desplazan hacia el personaje de "carne y hueso" (de nuevo evocamos a Unamuno). Diríamos, en el sentido heideggeriano, que este relato histórico coloca al "ser ahí", rezumando vida en su espacio cotidiano, para cuya captación es necesario aposentarse en la intimidad. 
Pero esa intimidad no se propone aislar al personaje de su cosmos social. Diríamos que ese trabajo intensivo de la hermenéutica microhistórica quiere ofrecernos un paisaje en su interna profundidad. A Menocchio, por ejemplo, no sería posible percibirlo sino desde su paisaje histórico cultural. Ese paisaje no es el espacio abstracto romántico o positivista, sino la vida donde mora lo local. Gracias a ese movimiento la geografía física da paso a una geografía más interior, donde la vida de un personaje nos revela un cosmos rico en complejidad.

La abundante tarea generalizante de las ciencias sociales modernas no ha hecho sino evadir el espacio local, epicentro de la vida "silenciosa", espacio del zócalo marino que nos metaforizó Miguel de Unamuno.

Lo intrahistórico es la "historia inconsciente", el avatar de los hombres que mueven el mundo sin más pretensiones que la de vivir, y lo cotidiano es ese hacer donde conviven la rutina y el cambio, lo que permite el continuum de la historia. ¿Qué es lo local? Francisco Zuluaga (2006) lo define así:

... un sitio o un lugar donde se localiza algo o alguien, sitio o lugar desde el cual algo o alguien toma posición frente a otros. Es pues un lugar referente, tanto para localizar a alguien (una comunidad por ejemplo) ubicada en dicho lugar, como para que ese alguien (esa comunidad) se localice y desde allí enfrente, se distinga, esté con otro(s) alguien, otras comunidades (3).

Como observamos, la localidad es la más cierta residencia del mundo. Porque si existiese un único mundo, ¿cómo lograríamos percibirlo? ¿Cómo podríamos asegurar su existencia? Pues, opiniones diversas concurren en las respuestas a esas preguntas. Una de ellas niega la existencia del universo, puesto que sostiene que toda existencia humana tiene experiencia en el lenguaje, y éste es puesto en acción. Cuando miramos somos hombres, no dioses. Por ello nuestra percepción tiene un radio muy localizado. Entonces, no existe sino el mundo que experimentamos y que podemos concretar mediante los signos. Pero ese lenguaje no es sino acción sobre la realidad en la que interactuamos. Es decir, lingua in situ.

El universo, pues, se concreta en un espacio. El universo es una suma interconectada de espacios, en la que algunos segmentos se han erigido como centro modelizador.

Esos fragmentos han sido en sus inicios comunidades que al amparo de instancias políticas, como son los estados, han elaborado la base refrendadora de las naciones, antagonizando permanentemente con otras fuerzas imaginarias plurales que son portadoras de otras miradas del espacio donde se urde la unidad comunal. 


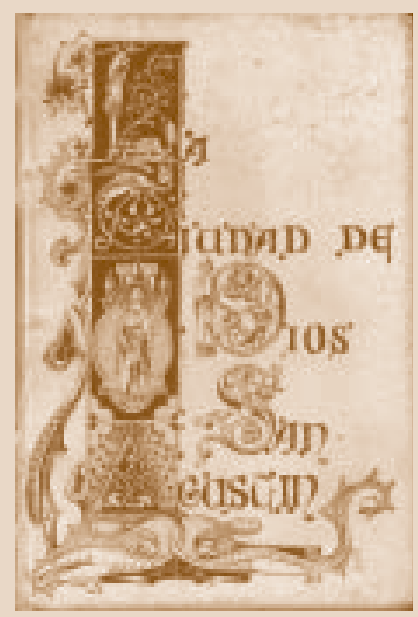

La universalidad es, entonces, una falacia, porque lo que existe es este cuerpo que dialoga con un espacio contentivo de una compleja matriz generadora de símbolos. Existimos nosotros, en permanente diálogo con la materialidad histórica que nos cobija ahora.

Esa materialidad tiene nombre. Ella misma se ha nombrado por obra y gracia de la historia. Pero la historia ha sido contada a la manera de una trama agonística, con curvas de tensión conflictual, que no hacen sino narrar la teleología (es decir, el proyecto) de una de esas protocomunidades que posteriormente terminó imponiendo su hegemonía. Una de esas hegemonías hizo de la cultura occidental el espacio centrípeto de la universalidad.

Todo comenzó en la unión del imperialismo romano con la iglesia cristiana. La leyenda de que Constantino se hizo cristiano a través de una epifanía, que le autoiluminó el camino a Cristo, es poco convincente. La solidaridad de la cruz con la espada obedeció más bien a un ideal ecuménico, donde la religión se convertiría en plataforma apuntaladora de un proyecto homogeneizador que trascendió al mismo imperio romano y se consolidó férreamente en la Edad Media. Y el gran ideólogo de ese proyecto fue San Agustín, quien, en su Ciudad de Dios, traza la primera teleología del Occidente. A partir de entonces la historia arma su arco desde donde saldría la flecha que tenía que atinar a la diana de la salvación, encarnada en el mito de Cristo, dios hombre. El futuro desplaza al pasado. La principal enseñanza es vivir para suscitar un porvenir prodigado bajo la fe cristiana. Dios nos tiene dispuesto un fin: la adscripción a una fe única nos lo garantizaba. Esa idea de ciudad deica encarnaba un concepto de nación universal, y también en una noción de comunidad cristiana, cuyos miembros eran indiferenciados.

El mito de Babel fue utilizado para anatematizar. Había que rescatar la unidad natural de dios, ésa que nos hacía habitantes de un único mundo.

Pero lo que nos hace singular es haber caído en ese proceso babelizador, no porque el hombre de por sí apueste por la incomunicación, sino porque él es por excelencia un ser que aspira a una particularidad, que se va moldeando en diversas instancias: en el vientre materno; desde allí emerge para hacerse de un espacio hecho de un barro subjetivo cultural e individual.

Yo soy de aquí, no de allá. Pero el aquí no se cierra; quiere dialogar con otras orillas; pero en igualdad de condiciones. Hay que revisar la prédica de la aldea global; ella no existe; más bien, lo que sentimos son miles de aldeas que luchan por su derecho identitario, prestas a compartir nuestros dioses, nuestros mitos, nuestras esperanzas.

Pero habrá que cuidarse de aquellos que sacrifican lo local por sus uto- 
pías cínicas: los nacionalismos, por ejemplo, que amurallados en sus espacios simbólicos pretenden cercar lo local, en procura de consolidar una hegemonía que se solapa en las banderas nacionales, en los himnos y en los equipos deportivos. Porque tan perversa es la globalidad como una nacionalidad que quiere hacer tabla rasa con esos espacios donde los seres experimentan su cotidianidad.

Queremos concluir nuestra exposición, arrimando nuestros argumentos al escenario latinoamericano, para procurar ver la posible vigencia de los conceptos aquí discutidos.

En otro texto (cfr. Medina, 2000) hemos alertado sobre el peligro de la enfermedad utópica. María Ramírez Ribes habla de una "perspectiva feliz" anunciada en toda utopía. Ese logro de la felicidad es una ingenuidad que siempre ha constelado el existir humano. Y de eso se han burlado Aldoux Huxley y buena parte de la cinematografía contemporánea: Blade Runner, Doce monos, entre otros. Cioran, en una postura cínica y realista, ha dicho que la ausencia del mal es inhumano. La salud no es un signo humano, sino privilegio de aquellos que no son hombres: los dioses, los héroes, los santos, etc. "Sean cuales fueren sus méritos, quien tiene buena salud siempre defrauda" (1993:107). La novela de Huxley ve "humanidad" en aquellos personajes que la máquina socializadora ha hecho distintos, con cojeras, con dolores muy concretos. La utopía es el ensueño nacido

... generalmente del sentido de fracaso del presente y, a lo largo de la historia, aparece en circunstancias conflictivas similares para suministrar, más que los mecanismos inmediatos para acabar con ellas, una imagen tranquilizadora del conflicto resuelto (Ramírez Ribes, 2005: 8).

La utopía sería, entonces, el calmante, la anestesia que hace olvidar el dolor, no la conciencia que nos hace asumirlo como instancia realísima a la que el ser se ve sometido cotidianamente. El ser vive en su carne, una carne histórica sobre la cual cae el tiempo inexorablemente. El relato utópico es la resaca que nos quedó de aquel Dios Titán, incapaz de concebirse como perdedor. Perder es un horror.

De ese horror nació la utopía de Latinoamérica. Ha sido trajinada por diversos discursos: los de Miranda, los de Bolívar, los de José Martí, los de Vasconcelos, etc. En todos ellos merodea la idea de la generalización de nuestra América Latina, obsesionada con un proyecto de integración, que desdibuja el complejo diferencial que caracteriza a todos los países de esta región. Una generalización que le tiene pánico a la intrahistoria, a la cotidianidad y a la localidad.

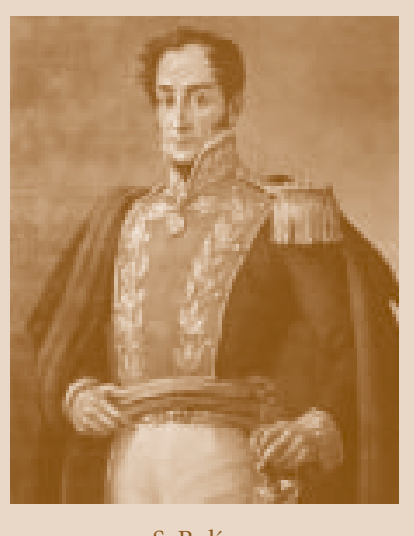

S. Bolívar 
Una fórmula que seduce a nuestros sociólogos y etnólogos es la del mestizaje, que diluye la carnadura vital de esos hombres que hacen andar la cotidianidad latinoamericanista, engranándola en un proceso generalizador que toma el camino de una mitificación ideologizante que los cosifica, llevándolo al espacio de la folklorización. Hay quienes quieren hacer la suma de la identidad latinoamericanista con los empobrecidos emblemas del charro mexicano, del macondismo colombiano, del gaucho argentino o del llanero venezolano, convirtiendo la vida de nuestras culturas populares en piezas de museo, cuya tradición no es presente, ni la "tradición viva" de la que nos habló Unamuno, sino pasado. Tal evento es más bien, según García Canclini (2003), "reserva imaginaria de discursos políticos nacionalistas", que crea el artificio de un espacio supuestamente consensuado, donde toda diferencia queda supeditada a la idea nación, para quien se inventó una idea estereotipada de pueblo. Ocurre, entonces, que "El pueblo es 'rescatado', pero no conocido" (García Canclini, 2003: 196).

\section{REFERENCIAS}

Aguirre Rojas, Carlos Antonio. 2003. "El queso y los gusanos: Un modelo de historia crítica para el análisis de las culturas subalternas". Revista Brasileña deHistoria vol. 23 No 145 , julio. São Paulo.

Bloch, Marc. 1988. Introducción a la historia. Madrid: Alianza.

Chartier, Roger. 1994. L'histoire aujourd'hui: doutes, défis, propositions. Valencia: Centro de Semiótica y Teoría del espectáculo de la Universidad de Valencia.

Cioran, E. 1993. La caída en el tiempo. Barcelona: Tusquet Editores.

García Canclini, Néstor. 2003. Culturas híbridas. Estrategias para entrar y salir dela modernidad. México: Grijalbo.

Ginzburg, Carlo. 1999. M itos, emblemas, indicios. M orfología ehistoria. Barcelona: Gedisa.

. 2000. El queso y los gusanos. Barcelona: Editorial Atajos.

Heller, Agnes. 1979. La revolución dela vida cotidiana. Barcelona: Editorial Materiales.

. 2002. Sociología de la vida cotidiana. Barcelona: Editorial Península. Levi, Giovanni. 1999. "Sobre microhistoria”. En Formas de hacer historia. Peter Burke (editor). Madrid: Alianza Editorial. Pp. 119-143.

Medina, Celso. 2000. La literatura frenteal pesimismo. Maturín, Venezuela: Universidad de Oriente.

Moreno, Julián Santano. 2003. "Menéndez Pidal y la filología del '98. Estado latente e intrahistoria”. Criticón, 87-88-89, pp. 787-798.

Ortega y Gasset, José. [1921] 2006. España invertebrada. Madrid: Espasa. 
Rabaté, Jean-Claud. 1999. "Idéologie et politique dans En torno al casticismo". En Crise intellectuelle y et politique en Espagne á la fin du XIX siécle. París: Editions du Temps.

Ramírez Ribes, María. 2005. La utopía contra la historia. Caracas: Fundación para la Cultura Urbana.

Sharpe, Jim. 1999. "Historia desde abajo". En Formas de hacer historia. Meter Burke (editor). Madrid: Alianza Editorial. Pp. 38-58.

Unamuno, Miguel de. [1895] 2000. En torno al casticismo. Madrid: Alianza. - [1896] 1958. "Sobre el cultivo de la demótica". Discurso leído en la Sección de Ciencias Históricas del Ateneo de Sevilla el 4 de diciembre. En O bras completas, VII, ed. de M. García Blanco. Madrid: Afrodisio Aguado.

1897. Paz en la guerra. Madrid: Lib. de Fernando Fe.

[1900] 1968. "Vida del romance castellano", en O bras completas, ed. Manuel García Blanco, t. IV. Madrid: Escelicer.

Veyne, Paúl. 1984. Cómo se escribe la historia. Foucault revoluciona la historia. Madrid: Editorial Alianza.

Zuluaga, Francisco U. 2006. "Unas gotas: Reflexiones sobre la historia local”. En: Historia y espacio, ISSN 0120-4661, № 27.

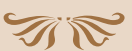

